\title{
Research on Music Education Teaching Methods Based on Virtualization Reality Technology
}

\author{
Sun $\mathrm{Si}^{1, \text { a }}$ \\ ${ }^{1}$ Department of Music, Hankou University, Wuhan 430000, Hubei, China \\ a10040143@qq.com
}

Keywords: Virtualization Reality Technology, Music Education, Teaching Strategy

\begin{abstract}
With the development of the schools information construction, there are the continued implementations of virtualization technology in a variety of business applications, which can integrate and deploy these resources, and improve equipment utilization. In this paper, we analyze the problems existed in traditional schools data center architecture, proposes the construction of new schools data center using virtualization technology from the aspects of virtualization framework, server resources integration, network configuration optimization, etc. Server virtualization integration could save resources, improve server utilization ratio, simplify the hardware maintenance and upgrades, reduce operating costs and improve maintenance efficiency. Music teaching strategies to implement research, summarize and generalize the implementation of policies and implementation requirements of music teaching, starting from the teaching objectives, teaching content, teaching environment, comprehensive different from teaching music lessons, music and other artistic disciplines as well as music and non-arts disciplines start, through detailed analysis of music-disciplinary teaching strategies and implementation requirements.
\end{abstract}

\section{Theoretical Introduction of Virtualization Reality Technology}

Virtualization is a broad term that refers to running in the virtual computing elements rather than on the basis of real basis. Specifically, in the form of virtualization technology to achieve is to join a virtualization layer in the system, the lower the resource abstraction into another form of resource for the upper using virtualization to simplify a management resource optimization solution. Nature of virtualization technology is a resource management technology, which aims to make more rational use of resources.

Virtualization reality technology as an emerging technology, it has resource virtualization, dynamic allocation of resources, the demand for self-service, network access facilitation, services and other characteristics can be measured. There are common virtualization infrastructure virtualization (server virtualization, network device virtualization, storage virtualization, etc.), system virtualization (virtual machine technology), and software virtualization (Java Virtual Machine). The resource scheduling means virtualization is based on a unified platform with clouds in real time on a variety of computing resources, efficient resource allocation and management, so that a variety of resources can achieve adequate and reasonable utilization ${ }^{[1]}$.

Through reality virtualization technology can help schools to upgrade and manage these distributed on the basis of system integration, and thus achieve effective integration of information systems, so that schools can grasp the initiative in information systems development. In particular, application virtualization technology to build the music education, facilitate technology management; more directly alter the performance of business applications and IT systems throughout the human system integration and remote access applications. By virtualizing application servers and storage, the successful centralized data storage system of schools management can make full sharing of data between the server resources, reduce the complexity of storage management. 


\section{Applications of Virtualization Reality Technology in the Music Education}

Server virtualization has multiple instances, isolation, CPU virtualization, memory virtualization, device and I / O virtualization, load balancing, unified management, rapid deployment and other features. We have introduced the experiences of Virtual Technology using in the schools data center storage, the core server, integration system, network application and remote access applications, server and database platform as well as the application effects, which make a useful exploration for the building and the development of music education, disaster recovery fault tolerance, zero downtime, zero data loss without the need for complex failover cluster or dedicated hardware, high security ${ }^{[2]}$. Fig. 1 shows the process of server virtualization.

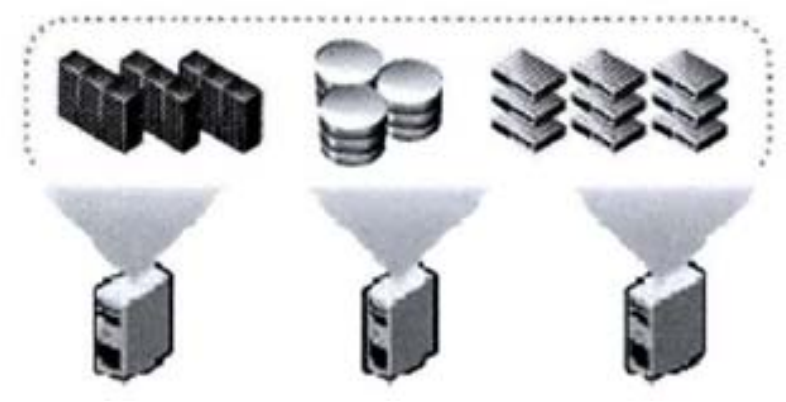

Fig. 1.The process of server virtualization

Storage virtualization technology due to the use of storage pools, data on the distribution of the disk array more disk, not only to improve performance, and capacity and management problems can be solved through automatic load balancing. Virtual memory system to build a fully redundant virtualized storage systems and storage virtualization technology architecture platform, two high-end disk array configuration, using management software provides fault tolerant data protection, automatic backup and restore functions, the schools will be integrated into a complete storage system performance storage resource pool, and the storage system to be optimized.

Virtual LANs and virtual private network also get a lot of applications, in order to improve the security of the schools network, using three core switches, according to the nature of the business will be divided into multiple network client VLAN, and configure access policy planning, control access VLAN between effective prevention and control of broadcast storms, and enhance the stability and reliability of the schools network. Schools currently used VPN technology for remote management and timely maintenance of information systems and the use of various application systems office, remote office to improve efficiency in real-time places, but also as to achieve internal digital library resource sharing and remote access to a schools important technology to improve resource utilization and facilitate queries to retrieve documents at home ${ }^{[3]}$.

\section{The Teaching Principles of Virtual Reality Technologies}

Music has depicted features, but the shape is depicted in the abstract, we need people with imagination can only appear in the brain being. Since each person's life experiences, emotional heritage, culture, nature-loving, live in different environments, they feel the music's emotional experiences are not the same ${ }^{[4]}$. The main principles are as follows:

Listening to music is always a prerequisite for the implementation of the teaching of music appreciation. Since high school students while listening to music students have enough patience and self-control, they are more concerned about the music lesson is writing music itself, rather than on the books introduction. Thus, the music appreciation course not advocate teacher tells occupy too much time listening to music students, and to promote the integrity of student work on music perception and experience. In the ever-changing modern society, the aesthetic criteria of art has become increasingly blurred in the continuing commercial speculation, the aesthetic orientation of contemporary youth as "the music of the trend of" constantly changing. An excellent piece of music to show the hot feelings, contain a good moral, can become high school students living in a spiritual 
medicine. Lesson planning process should select the "ideological and artistic unity" of outstanding Chinese and foreign musical works for the students, for students this noble sentiment, good temperament, health aesthetics have an essential role. Fig.2 shows the main principles of virtualization platform.

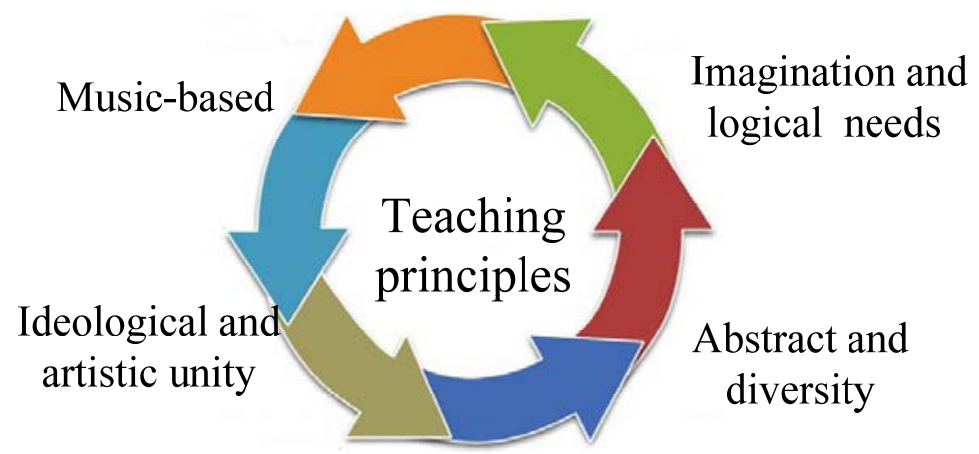

Fig.2.The main principles of virtualization platform

Both physical and mental aspects of the students are gradually maturing youth, they will focus on things they are interested in, and willing to make them deep, clear and unique thinking. This requires teachers to high school students based on physical and psychological characteristics, in the music classroom for students to create a harmonious, democratic atmosphere for the exchange, encouraging students to give full play to the creativity and imagination, revealed his true feelings at the time to appreciate the music. The ultimate goal of music appreciation is to fulfill the spirit of sublimation and rational comprehension, teachers need to develop students' logical thinking on the basis of image thinking on students, music appreciation achieve rational level, so vivid emotional experience and accuracy the perfect combination of a deep rational knowledge, in order to achieve perfection and aesthetic leap mental activity.

\section{The Implementation of Music Teaching Methods}

The virtualized data center architecture, the distinguishing feature is that all the physical equipment and lines are redundant as possible. Physical server connected to the network is dual-link, the connection with storage cabinets are also dual link; all virtual servers are running on a unified resource pool consisting of multiple physical servers, after any one physical server goes down, related virtual server can automatically migrate to other normal physical server ${ }^{[5]}$. Fig. 3 shows the topologies of schools virtualized data center.

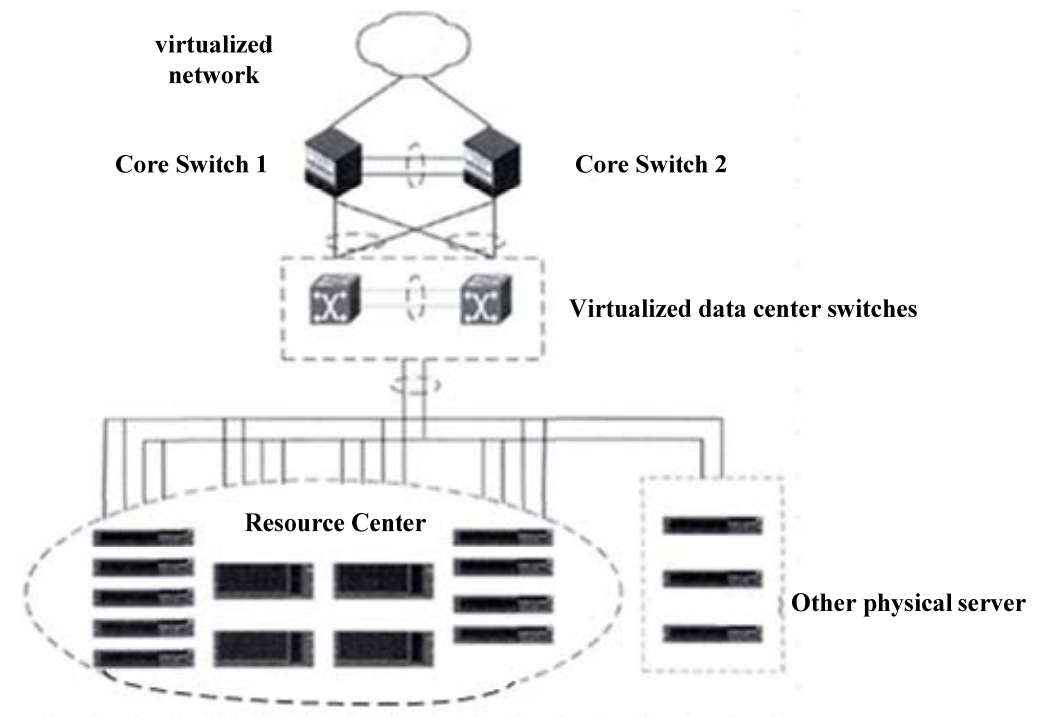

Fig. 3.The the topologies of schools virtualized data center

The basic contents of the music curriculum are as follows: Music appreciation is an important part of the high school music teaching is an important way to cultivate students' ability to feel the 
music and aesthetic ability. Students have a good ability to appreciate music, enrich their emotional, strive to improve literacy, promote health, improve the formation of personality has important significance. Singing is a very practical learning content, but also the most easily accepted and happy student performances participation. Open singing course, reflects the continuity of the primary and secondary schools of music teaching. Singing helps develop students' skills, develop students' interest in the song singing hobby, more conducive to students' performance to explore the potential and creative potential.

Instrumental music to stimulate students' interest in learning, improve understanding of music, expression and creativity has a very important role. Instrumental music appreciation teaching content and teaching, singing, writing and so closely, is an effective way to train musical performance ability and aesthetic ability. Learning instrumental, not only to master twelve instruments playing skills, but to play a musical instrument through and establish a good aesthetic taste, experience the euphoria of cooperation with others. This is a traditional music education in primary and secondary schools that are not new elective series, as innovative talent has a special significance.

Music and dance is intimate sister arts, the creation of a series of courses in music, reflecting the trend of comprehensive art education. Students can get to know both the art of dance through music, but also can enhance the interest in learning the art of dance through the course, experience the beauty of the art of dance. Elective opened for students learning numerous contacts and comprehensive art genre offers the opportunity of a strong musical patterns and musicals, historical drama and drama, stylish, modern movies and television arts at once with some strong main content. It will effectively broaden their artistic visions that they become integrated in order to showcase the art of the stage

\section{Conclusions}

Music not exist in isolation, it is difficult to let go of the other arts have a contact. Music learning can't be a single, teaching music is rich, integrated. Students receive music education on ways and means to directly influence their understanding of music and sensibility, but also on the development of musical ability has inspired effect on other aspects of music literacy subject has been raised outside the role. In this paper, application of virtualization technology in the music education construction can make the physical facilities abstract, and avoid all sorts of problems in the process of the construction of the platform due to the deployment of physical resources. We have built the platform of storage virtualization with the technology of storage virtualization, and put all the storage systems in our schools into one storage pool in order to satisfy the needs of broad perspective, rich connotations, high availability the information systems.

\section{References}

[1] Toby J.V, Anthony T.V. Green IT-Reduce Your Information System's Environmental Impact While Adding to the Bottom Line. New York: McGraw-Hill Osborne Media, 2008.

[2] Jha AK, DesRoches C M, Campbell E G, et al. Use of electronic health records in US schools. New England Journal of Medicine, 2009, 360(16): 1628-1638.

[3] Janet R. Barrett. Planning for Understanding: A Re-conceptualized View of the Music Curriculum. Music Educators Journal, Vol. 91, No. 4 (Mar., 2005). 21- 25.

[4] Bhardwaj S, Jain L, Jain S. Cloud computing: A study of infrastructure as a service (IAAS). International Journal of engineering and information Technology, 2010, 2(1): 60-63.

[5] Xing Y, Zhan Y. Virtualization and Cloud Computing. Future Wireless Networks and Information Systems, 2012: 305-312. 